\title{
Aortic aneurysm and mitral regurgitation as first manifestations of ankylosing spondilitis
}

\author{
Ertan Demirdaş ${ }^{1}$, Kıvanç Atılgan' ${ }^{1}$ Utkan Sevuk ${ }^{1}$, Oğuz Taşdemir ${ }^{2}$
}

\footnotetext{
1) Bozok University Research and Application Hospital and Cardiovascular Surgery / Yozgat / Turkey

${ }^{2)}$ Medicana International Hospital, Cardiovascular Surgery, Prof. Dr., Ankara, Turkey
}

\begin{abstract}
Ankylosing Spondilitis is a systemic inflammatory disease that involves the whole spine and sacroiliac joints. Cardiac manifestations include mitral regurgitation, aortic regurgitation, conduction abnormalities, atrial fibrillation, myocardial dysfunction and pericarditis. A 72 year-old male referring to our department because of dyspnea and mediastinal widening at chest radiography and having a diagnosis of aortic aneurysm and mitral regurgitation is presented as a case report.
\end{abstract}

Keywords: Ankylosing spondilitis, mitral regurgitation, aortic aneurysm, complication

A 72 year-old male was referred to our department because of dyspnea and mediastinal widening at chest radiography. Computed tomography (CT) scan of the chest with contrast revealed a $70 \times 65 \mathrm{~mm}$ saccular aneurysm of the arcus aorta with intraluminal thrombus and ascending aorta dilatation with a diameter of $45 \mathrm{~mm}$ (Figure 1). Echocardiography revaled normal left ven- tricular systolic function and severe mitral regurgitation. The patient has been suffering from low back pain for 10 years which have been considered to be associated with age-related degenerative changes and overlooked by the patient and the physicians. Preoperative Rheumatology consultation was requested to exclude vasculitis and the work-up revealed ankylosing spon- 
dylitis (AS). Patient underwent an uneventful surgery. The aneurysm was repaired by Dacron patch-plasty. Leaflets of the mitral valve was severely thickened and was not suitable for repair. Thus, mitral valve was replaced using a mechanical valve. CT scan obtained 1 year after the operation demonstrated no abnormal findings at the repair site after patch angioplasty (Figure 2).

AS is a systemic inflammatory disease that involves the whole spine and sacroiliac joints. Cardiac mani-



Figure 1.

\section{References}

1. Yuan SM. Cardiovascular involvement of ankylosing spondylitis: report of three cases. Vascular. 2009;17(6):342-54.

2. Roman MJ, Salmon JE. Cardiovascular manifestations of rheumatologic diseases. Circulation. 2007;116(20):2346-55.

3. Gornik HL, Creager MA. Aortitis. Circulation 2008;117:3039-51 festations include mitral regurgitation, aortic regurgitation, conduction abnormalities, atrial fibrillation, myocardial dysfunction and pericarditis. ${ }^{[1,2]}$ It should be kept in mind that, although extremely rare, aortic aneurysms and cardiac diseases may be the first manifestation of the AS and aortic aneurysms secondary to inflammatory diseases including AS are associated with an increased risk of relapse. ${ }^{[1,3]}$ Thus, patients should be followed up closely in the post-operative period.

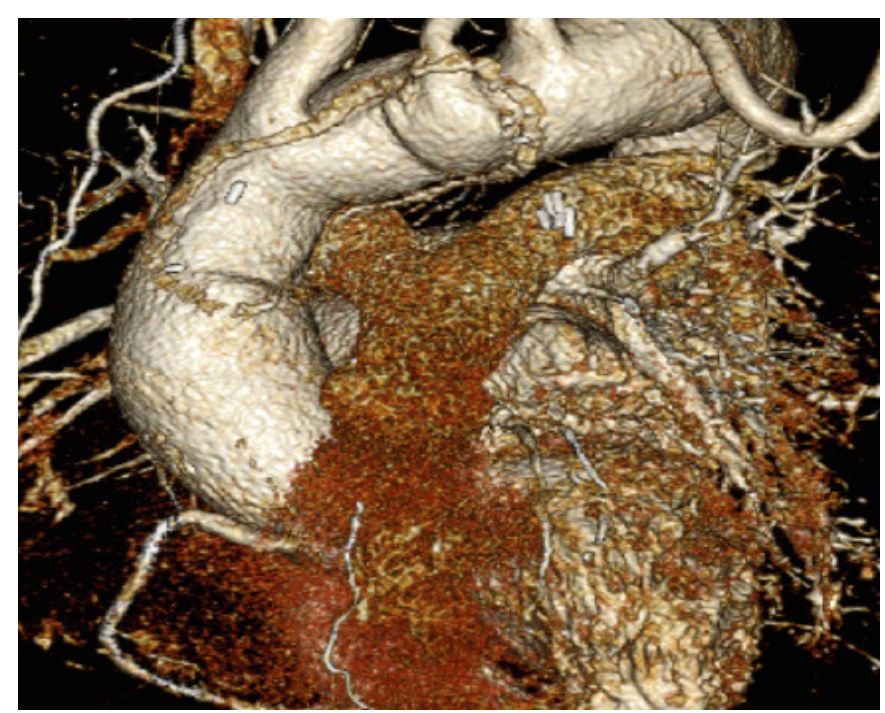

Figure 2.

Received: 24/06/2016

Accepted: 22/08/2016

Published: 15.09.2016

Disclosure and conflicts of interest:

Conflicts of interest were not reported.

\section{Corresponding author:}

Dr. Kıvanç Atılgan

Mail: kivancatilgan@gmail.com

Demirdaş E, Atılgan K., Sevuk U., Çiçekçioğlu F. Aortic aneurysm and mitral regurgitation as first manifestations of ankylosing spondilitis EJCM 2016; 04 (3): 71-72. Doi: 10.15511/ejcm.16.00371. 